\title{
A DIREÇÃO DO TRATAMENTO NA CLÍNICA DOS FENÔMENOS PSICOSSOMÁTICOS
}

\section{The Direction of the Clinical Treatment of Psychosomatic Phenomena}

\author{
La Dirección del Tratamiento Clínico de los Fenómenos \\ Psicosomáticos
}

\section{La Direction du Traitement dans la Clinique des Phénomènes Psychosomatiques}

\begin{abstract}
Resumo
O objetivo deste relatório de pesquisa é discutir o manejo da transferência em pacientes acometidos pelos fenômenos psicossomáticos, demonstrando que a operação analítica nessa clínica só é possível a partir da função desejo do analista. A escuta de uma paciente acometida por urticária, doença classificada como psicossomática pelo saber da medicina, coloca em evidência a psicanálise como um discurso que pode operar alguma mudança no sujeito em relação ao seu sofrimento. Ressalta-se que o manejo da transferência é particularmente difícil nestes casos, pois o paciente busca uma resposta para seu mal e sua fala é circunscrita ao real do corpo, sempre em referência a este, apontando para um gozo específico fixado em um pedaço de carne, que, como ensina Lacan, é próprio ao fenômeno psicossomático. A análise deste caso mostrou que a possibilidade de circulação da palavra a partir da regra fundamental da psicanálise, a associação livre, a qual esteve fortemente comprometida durante o início do tratamento por conta de inúmeras falas quase que exclusivamente referentes à enfermidade do corpo, permitiu à paciente construir um sintoma analítico e um saber sobre a sua doença ao trazer questões familiares que favoreceram inúmeras associações, fazendo avançar a análise em direção a uma nominação, onde o Nome-do-Pai pode operar para ela.
\end{abstract}

Palavras-chave: desejo do analista; tratamento; fenômeno psicossomático; gozo; sujeito.

\begin{abstract}
The objective of this research report is to discuss the handling of transference in patients affected by psychosomatic phenomena, demonstrating that the analytical operation in this clinic is only possible from the analyst's role desire. Listening to a patient affected by hives, a disease classified as psychosomatic medicine as knowledge, highlights psychoanalysis as a speech that can operate any change in subject in relation to his suffering. It is emphasized that the management of the transfer is particularly difficult in these cases, because the patient seeks an answer to his disease and his speech is limited to the actual body, always in reference to this, pointing to a specific enjoyment set in a piece of meat which, as Lacan teaches, is proper to the psychosomatic phenomenon. The analysis of this case showed that the possibility of movement of the word from the fundamental rule of psychoanalysis, free association, which was strongly compromised during the start of treatment due to numerous speeches almost exclusively related to bodily infirmity, allowed patient build an analytical symptom and know about their disease by bringing family issues that favored many associations in advancing the analysis toward a nomination, where the Name-of-the-Father can work for her.
\end{abstract}

Keywords: analyst's desire; treatment; psychosomatic phenomena; joy; subject.

\section{Resumen}

El objetivo de este informe de pesquisa es debatir el manejo de la transferencia en pacientes que sufren fenómenos psicosomáticos demostrando que la operación analítica en esa
Relato de pesquisa
1) Psicóloga. Psicanalista em formação. Doutoranda pelo Programa de Estudos Pós-Graduados em Psicologia Psicologia Social da Pontifícia Universidade Católica de São Paulo. Mestre pelo Programa de Pós-Graduação em Psicologia da Universidade Federal do Pará

2) Professora da Faculdade de Psicologia e do Programa de Pós-Graduação em Psicologia da Universidade Federal do Pará, onde Coordena o Laboratório de Clínica do sujeito: sintoma, corpo e instituição. Psicanalista Membro da Escola de Psicanálise Letra Freudiana.
Recebido em: 01/06/2012 Revisado em: 05/09/2013 Aceito em: 29/09/2014 
clínica sólo es posible a partir de la función deseo del analista. La escucha de una paciente acometida por urticaria, enfermedad clasificada como psicosomática por el saber de la medicina, pone en evidencia el psicoanálisis como un discurso que puede operar algún cambio en el sujeto en relación a su sufrimiento. Se destaca que el manejo de la transferencia es particularmente difícil en estos casos, pues el paciente busca una respuesta para su mal y su habla es circunscrita a la realidad del cuerpo, siempre en referencia a este, apuntando al goce específico fijado en un pedazo de carne, que como enseña Lacan, es propio al fenómeno psicosomático. El análisis de este caso revela que la posibilidad de circulación de la palabra, a partir de la regla fundamental de la psicoanálisis, a libre asociación, que se ha comprometido firmemente durante el tratamiento, por causa de innumerables hablas, casi que exclusivamente referentes a la enfermedad del cuerpo, permitió a la paciente a construir un síntoma analítico e un saber sobre su enfermedad al traer cuestiones familiares que favorecieron inúmeras asociaciones, haciendo avanzar el análisis en dirección a un nombramiento, donde el Nombre-del-Padre puede operar en ella.

Palabras clave: deseo del analista; tratamiento; fenómeno psicosomático; goce; sujeto.

\section{Résumé}

L'objectif de cet rapport de recherche est de discuter la manipulation du transfert des patients affectés par les phénomènes psychosomatiques, démontrant que l'opération analytique dans cette clinique n'est possible que par le désir de l'analyste. L'écoute d'un patient atteint d'urticaire, classés comme une maladie psychosomatique par la médecine, met en évidence la psychanalyse comme un discours qui peut fonctionner un changement dans le sujet relatif a sa souffrance. Il est souligné que la manipulación du transfert est particulièrement difficile dans ces cas parce que le patient cherche une réponse à sa maladie et son discours est limitée a réalité du corps, toujours en référence à cette corps, pointant vers une jouissance spécifique fixée sur une pièce de viande, comme Lacan enseigne qu'il est propre de phénomène psychosomatique. L'analyse de cette affaire a montré que la possibilité de circulation de la parole à la règle fondamentale de la psychanalyse, la libre association, qui a été fortement engagé pendant le début du traitement en raison de nombreux discours presque exclusivement liées à infirmité physique, a permis le patient construire un symptôme analytique et connaître leur maladie, à partir des questions relatives a famille qui ont favorisé de nombreuses associations et progresser l'analyse vers une nomination, où le Nom-du-Père peut travailler pour le patient.

Mots-clés: le désir de l'analyste; traitement; phénomène psychosomatique; jouissance; sujet.

Este trabalho é fruto da pesquisa que resultou em uma dissertação de mestrado intitulada $O$ manejo da transferência na clínica dos fenômenos psicossomáticos: $o$ que pode ser enodado, onde se investigou as particularidades do manejo da transferência na clínica dos fenômenos psicossomáticos (FPS) recolhendo, de um caso clínico, as interrogações e elaborações teóricas aqui apresentadas. Considerando que, no trabalho de pesquisa e/ ou investigação psicanalítica, não há distinção metodológica a ser feita entre a investigação e o tratamento, utilizamos o método clínico próprio à investigação em psicanálise, conforme nos ensina Freud (1912/1996c), onde é preciso adiar as conclusões ou elaborações para o só - depois da experiência analítica. Nesse método, a associação livre e o trabalho em transferência devem ser preservados, para que seus efeitos possam produzir uma escrita. A investigação ocorreu como desdobramento de uma pesquisa mais ampla sobre "O Sintoma do Corpo", desenvolvida na Clínica de Psicologia da Universidade Federal do Pará, cujo objetivo era investigar os mecanismos subjetivos que engendram as manifestações sintomáticas do corpo, para as quais não se encontra um referente orgânico. Nesta investigação, o tema da psicossomática esteve presente, pois os pacientes encaminhados para atendimento eram frequentemente assim diagnosticados.

Pretende-se aqui, através de recortes de um caso atendido no âmbito da pesquisa mencionada, abordar a direção do tratamento que possibilitou um reposicionamento do sujeito em relação ao seu sintoma, ressaltando a importância da sustentação da escuta na direção do tratamento. O contexto em que o atendimento da paciente se deu não é indiferente, pois certamente incidiu sobre o desenrolar da análise, seja nas dificuldades encontradas, seja nas vias que puderam ser abertas. Destacamos aqui, em particular, a relevância da função desejo do analista na escuta dessa paciente, a qual nomearemos de Paula, portadora de uma urticária recorrente, considerada pelo DSM-IV (2002) como um transtorno somatoforme, ou doença psicossomática do sistema dermatológico.

Paula apresentava uma fala circunscrita à doença, não estabelecendo qualquer articulação das crises com os acontecimentos da sua história, permanecendo aprisionada às manifestações do corpo. Segundo alguns autores lacanianos como Wartel et al. (2003) e Nicolau e Guerra (2012), a ausência de um acontecimento, ao qual a doença possa estar referendada, dificulta a associação livre, implicando em maior dificuldade na condução do tratamento. Por outro lado, isso permite, de certa forma, estabelecer a diferença das afecções psicossomáticas com os sintomas de conversão histérica, pois estes, diversamente daqueles, fazem referência a um acontecimento na história do sujeito.

Deste modo, para compreender a dificuldade no manejo da transferência com pacientes acometidos por estas doenças, delimitamos, em primeiro lugar, a diferença entre 
sintoma conversivo e fenômeno psicossomático, apontando a aproximação destes com as neuroses atuais. Em seguida, discutiremos o manejo da transferência na clínica com pacientes acometidos por FPS, ressaltando a importância do desejo do analista, este que, em última instância, opera na cura.

\section{Nas Trilhas do Corpo: Neuroses Atuais, Sintoma Conversivo e Fenômeno Psicossomático}

Sabe-se, desde Freud (1905/1996b), que o sujeito se constitui a partir de seu corpo, à medida que este vai sendo bordejado pela pulsão, constituindo suas zonas erógenas para obter satisfação. Há uma montagem entre o corpo dos instintos e o corpo pulsional, no qual a pulsão nunca será satisfeita por completo, mas apenas parcialmente. Esta montagem não é fixa como nos instintos e, conforme observou Lacan (2008) no Seminário Os quatro conceitos fundamentais da psicanálise, ocorre como em um circuito, num vaivém que retorna sempre ao ponto de partida, reiniciando continuamente todo o circuito em busca de satisfação. Sobre essa montagem, nos diz o autor: "Não é uma montagem concebida numa perspectiva referida à finalidade. Esta perspectiva é a que se instaura nas teorias modernas do instinto, onde a presentificação de uma imagem de montagem é inteiramente captadora" (Lacan, 2008, p. 167). A impossibilidade de obter satisfação completa devese à queda, no processo de clivagem do aparelho psíquico, do objeto para sempre perdido, o objeto a, causa de desejo, como nos ensinou Lacan (2005). Por essa impossibilidade imposta, o sujeito vai se valer de seus sintomas, atos falhos, chistes e sonhos para tentar obter algum modo de satisfação pela via da substituição. Mas, no FPS, onde não está presente um processo de substituição, que processo estaria implicado e que tipo de satisfação?

Quando falamos em FPS, não é possível dizer que estamos diante de um sintoma conversivo. Este se manifesta como uma formação do inconsciente, pois conserva uma relação com o romance edípico, obedecendo aos mecanismos da metáfora e da metonímia, segundo Lacan (1998). Dessa forma, o sintoma aparece como o retorno do recalcado, permitindo, parcialmente, uma satisfação pulsional. O FPS, em contrapartida, não obedece a essas mesmas leis e aparece como uma tentativa de satisfação que não passa pelo encadeamento simbólico, estando, segundo Lacan (2008) na mesma série da debilidade mental e da psicose.

Essas elaborações lacanianas remetem ao que Freud (1895/1996a) formulou acerca de afecções que se manifestavam no corpo do sujeito e que ele denominou de neuroses atuais, cuja descrição muito se aproxima do FPS. Freud nomeou-as dessa maneira porque faziam referência a uma atualidade, por não guardarem relação com a história do sujeito. Além disso, elas indicavam que a satisfação pulsional, que deveria estar restrita às zonas erógenas, pode ser obtida por qualquer órgão, mostrando que o corpo apresenta um ponto complacente para o seu adoecimento. Isso faz referência a um masoquismo corporal, fato que levaria o corpo a gozar, induzindo o paciente a pagar a dívida daquilo que não foi simbolizado. Lacan fez uma releitura do conceito de masoquismo, articulando-o à pulsão de morte para formular a noção de gozo, que, mais tarde, iria constituir o que ele designou de campo lacaniano. Estas concepções nos permitem pontuar algumas questões em relação ao atendimento de Paula, cujo corpo era entregue às doenças, das quais não conseguia (ou não desejava) se desvincular. Foi com a queixa de não encontrar resposta para seu mal que chegou ao atendimento psicológico, após percorrer diversos especialistas que não the deram um diagnóstico preciso. Mas, de fato, como diz Lacan (2001) em "O lugar da psicanálise na medicina", o que ela desejava era ser autenticada no lugar de doente. A escuta analítica vem marcar uma diferença com o que ela havia obtido até então, quando o que se ouvia não era um sujeito desejante, mas sim um corpo, tomado como um pedaço de carne a ser manipulado e usado, submetido ao Outro que supostamente detém um saber sobre ele.

Paula chegou ao tratamento com um pedido de resposta acerca da sua doença, pois não estava disposta a continuar a tomar os medicamentos receitados pelos médicos para o tratamento de suas afecções. Diante desse fato, podemos assinalar que o saber médico tende a suprimir os sintomas e não tomá-los como uma via para o sujeito comparecer com o seu desejo. Promove, muitas vezes, uma massificação dos atendimentos, alienando ainda mais o paciente que se queixa de enfermidades psicossomáticas, por meio do uso de medicação ou pelos diagnósticos totalizantes, que ocupam o lugar de resposta que lhe é demandado. A psicanálise, diferentemente da posição médica, opera no sentido de possibilitar que o analisando enderece o seu dito ao sujeito, suposto saber constituído em análise, para que seja enviado ao dizer que diz respeito à pergunta sobre o seu desejo.

Diversamente do médico, o analista busca operar a partir da não resposta, da não erradicação do sintoma, possibilitando ao sujeito que se queixa e que não se implica com o mal que o acomete, uma perspectiva de enlaçamento com o Outro por um caminho onde o inconsciente possa manifestar-se. Wartel et al. (2003) relata que os psicanalistas não devem ter o mesmo posicionamento dos médicos, no sentido de dar respostas e diagnósticos fechados para as doenças ditas psicossomáticas, mas sim endossar "essa fraqueza irredutível da não resposta. É uma posição de ética" (Wartel et al., 2003, p.15). 
A esse respeito, Lacan (2009) formula algumas elaborações sobre a questão do saber na transferência em análise. Aponta a necessidade de existência de uma ignorância essencial para o seu curso, pois, enquanto o médico se coloca na posição de responder à demanda do paciente, o psicanalista deve operar como aquele que nada sabe, ou seja, como possuidor de uma ignorância douta. Esse lugar poderá levar o sujeito a se implicar com o seu sofrimento.

Observamos que, diante da entrega da paciente à doença, que a enlaçava ao outro na busca de autenticação para o seu mal, sua fala era circunscrita às afecções, havendo aí também uma satisfação. Por isso, apesar de buscar, pela via do tratamento psicológico, apaziguar o seu sofrimento, continuava querendo encontrar no saber da medicina, a resposta para sua cura. Certo dia, a paciente refere que parece ter algo dentro de si: "Algo que vem de fora e toma conta de mim", dizia ela, como se não tivesse nenhuma implicação com mal que a incomodava. Não saber nomear essa "coisa" externa a si mesma, coisificando o que a invadia, demonstrando a incidência ali de qualquer coisa da ordem do real, do objeto a, que como nos ensina Lacan, é algo irrepresentável e inominável para o sujeito, que não cessa de não se escrever, pois é da ordem do impossível, não cedendo à interpretação pela via do significante.

A fala em círculo, que não desliza, aponta para a gelificaçãodacadeiasignificante,promovendoumaholófrase, a qual consiste em um congelamento entre o primeiro par de significantes S1-S2. Esse modo de funcionamento remete a uma falha na inscrição do significante Nome-do-Pai, que deveria estar ex-sistindo à cadeia para dar consistência à realidade (Lacan, 2008); com isso, não foi permitido que o sujeito aparecesse entre um significante e outro, porque não se punha em jogo a sua afânise, isto é, o sujeito não desaparece sob um significante que o represente para outro significante. Destarte, através desse não comparecimento, a fala permanecia atrelada ao gozo mortífero e avassalador do Outro, mas com uma possibilidade de simbolização, pois, diferentemente do que ocorre na psicose, o significante Nome-do-Pai não se encontrava foracluído, já que houve apenas uma inadvertência na sua inscrição. Isso no caso, da paciente, que era neurótica, não implicando, porém, que o FPS não possa estar presente na estrutura psicótica, porém, o que queremos sublinhar é o fato de que o seu mecanismo de engendramento não necessariamente exclui a metáfora paterna.

Uma satisfação era também percebida ao demandar uma resposta à analista para o mal que a acometia. Essa satisfação em buscar autenticação para as suas enfermidades, como também nos diz Ornellas (2004), remete à fixação a um gozo específico do FPS, que coloca o sujeito entregue ao gozo no campo do Outro e, assim, ao real, pois não foi capaz de simbolizar todos os significantes advindos das relações precoces de sua história. Esse gozo retorna sobre outros órgãos do corpo porque não permaneceu restrito às zonas erógenas em função de uma falha no recobrimento do corpo pela linguagem. A fixação de gozo colocou-se como um impasse na direção a ser dada ao tratamento, já que a paciente não conseguia alcançar a esfera subjetiva, mantendo-se presa ao mal-estar corporal, levando a analista a se indagar sobre como o manejo da transferência poderia restituir a subjetivação do seu sofrimento por meio da associação livre, para que algo do inconsciente pudesse ser articulado, produzindo um sintoma analítico endereçado à analista com a possibilidade de elaboração.

Trata-se de uma fixidez de gozo no corpo, ou seja, de um gozo como uma imposição do Outro. O FPS é da ordem do sem sentido, pois transborda do real, não permitindo que o sujeito se implique com sua doença. Significa que, pela dor, que é o limite entre o prazer e o gozo, uma nova constituição de unidade corporal organizou-se de maneira falha, pois o sujeito faz laço social através da enfermidade como uma possibilidade de sustentação egóica, trazendo um escrito feito no corpo de algo que não foi simbolizado no campo da linguagem (Nicolau, 2008). Assim, avançaremos nesse trabalho, na tentativa de pensar a dificuldade imposta na direção do tratamento com estes pacientes.

\section{O Fenômeno Psicossomático em Transferência}

No atendimento de Paula, o desafio era como fazer emergir o sujeito alojado no dito aprisionado no gozo da doença, que busca resposta para seu sofrimento como se fosse invadido por algo que não lhe diz respeito. $\mathrm{O}$ endereçamento da fala do sujeito ao analista é fator preponderante na instalação da transferência, mas para que ele se implique é preciso que surja como dividido, como sujeito desejante. Se isso não ocorre, há consequências, ou seja, há uma dificuldade a mais na análise por não haver a produção de uma suposição de saber ao analista.

Esta é uma clínica desafiadora porque a fala é endereçada pela via da escrita no corpo e não pela via da transferência de amor e de saber, com a produção do sujeito suposto saber, onde o analista é convocado a ocupar o lugar do Outro, permitindo que o analisante associe livremente e possa se endereçar ao Outro do seu próprio inconsciente. O dito sobre o FPS diz respeito a uma escrita ilegível, precisando ser decifrada, para ser lida, a fim de ascender ao nível do significante passível de deslizamento na cadeia e de produção de sentido. Trata-se de uma fala vazia que não faz laço social e não possibilita um manejo pela via do simbólico na experiência de análise. O desejo do analista deve operar, apontando a divisão do sujeito, para que remeta a fala ao seu desejo, a um dizer. 
Paula, ao falar de suas visitas aos médicos, evidencia, em determinado momento, a questão da suposição de saber. Nesse caso, a possibilidade de construção de um saber está do lado do sujeito e não do analista, já que o analisando pode empreender um trabalho psíquico quando enuncia. De acordo com Ornellas (2004), ocorre uma subversão na relação do sujeito com o saber durante a análise. $\mathrm{O}$ gozo promove, concomitantemente, uma inclusão e uma exclusão, pois mostra o resto da divisão do sujeito e possibilita uma inscrição que opera no lugar de causa de desejo. Enquanto isso, o desejo do analista, sustentado pelo semblante de objeto a, opera no sentido de sustentar a fala que não articula um sintoma analítico, na tentativa de levar o sujeito a fazer outro tipo de laço através do seu discurso, isto é, possibilitar um giro em um dito, que comparece na análise, fortemente atrelado ao saber médico.

A certa altura da análise, apesar de continuar falando de suas doenças, a paciente evocou questões familiares, tal como o fato de não ter sido reconhecida e registrada pelo próprio pai, que a abandonou. Paula falava que o seu pai fora o seu avô, pois este a criou como uma filha, no entanto, enfatizou que a ausência do pai biológico lhe fizera falta, visto que nunca a tinha reconhecido como filha, pois foi "abandonada". Nesse caso, a função paterna foi exercida pelo avô e houve a inscrição do significante Nome-do-Pai, mas de maneira falha. $\mathrm{O}$ fato de ter sido ignorada pelo pai biológico e, de com ele não ter convivido, nos leva a pensar em uma marca promovida nessa paciente, mas uma marca que remete a um hieróglifo, pois não é da ordem do simbólico, daquilo que diz respeito ao significante e que é passível de ser lido e interpretado, ou seja, gera uma falha na inscrição da metáfora paterna. Aparece um traço no real, o qual, estando fora da linguagem, encontrará no corpo sua via de manifestação. Paula apresenta, através da fixação ao gozo específico de sua afecção de pele, o que foi vivenciado como abandono. Lacan, na Conferência de Genebra sobre o Sintoma (1993), diz-nos que o FPS aparece como um présignificante que não se dá a-ler, pois está marcado no real do corpo, como um número, remetendo a uma contagem de um a um, sem estarem relacionados em uma cadeia de significantes.

Em certa ocasião, a paciente relatou estar engordando e que sua taxa de triglicerídeos havia aumentado, alteração atestada por um exame e afirmou que as mudanças deviamse a uma dieta que lhe fora indicada para ganhar peso, já que estava muito magra, o que a levara a viciar-se em massa. Foi-lhe perguntado o que significava ser viciada, ela respondeu que ser viciada em alguma coisa representava ser dependente de algo e não ter controle sobre isso. Foi-lhe indagado novamente se havia algo mais que demonstrasse o seu vício e ela disse que talvez estivesse viciada em tantas doenças e médicos. O aparecimento desse significante apontava para um deslocamento do vício em médicos e exames para outro: a comida. Temos aí uma representação que culminou em outro extremo, que a levou a aumentar muito de peso. A paciente parecia, de maneira contraditória, ter um gozo em informar que agora apresentava um "verdadeiro" problema de saúde, atestado por exames. No entanto, referiu também uma possibilidade de mudança, pois havia voltado a trabalhar e pretendia retomar os estudos no ano subsequente. Essa fala denota que uma mudança de posição subjetiva em relação ao seu adoecimento não houve de fato, visto que apenas deslocou seu "vício" para outro lugar, demonstrando que não houve implicação com o seu sofrimento.

A mudança de sua posição subjetiva começou a ocorreu quando passou a trazer questões familiares, articulando-as a sua história e começou a falar menos sobre a sua doença, momento em que a manifestação do FPS no seu corpo começou a mudar, pois a urticária começou a desaparecer. Consideramos que foi a partir do aparecimento do significante viciada, que seu processo de análise se iniciou de fato, pois foi isso que permitiu a associação com os extremos cuidados que precisava ter com a família, particularmente no período dos atendimentos, especialmente com o filho caçula, para que não permanecesse abandonado como ela, que também estava, há muito tempo, viciada em repetir o abandono quando seus ex-maridos se envolveram com amantes e a deixaram. Essas considerações denotavam a sua falta de implicação com esses acontecimentos, numa posição histérica queixosa e vitimizadora.

Desse modo, o sujeito acometido pelo FPS apresenta a possibilidade de entrar em análise, consistindo em colocar em discurso a marca quase que hieroglífica que está no corpo, pois esse fenômeno é passível de se localizar no campo da linguagem através da indução significante, pois é efeito do significante. Lacan (2008) assinala que a psicossomática não é um significante, pois só é concebível à medida que, não havendo a afânise do sujeito, algo se passou a partir da indução significante. Percebe-se que menciona uma necessidade interessada na função do desejo no caso da enfermidade psicossomática. Desse modo, isso significa que pode haver uma remontagem à cadeia, pois o fenômeno não é sem a linguagem e sem o sintoma.

O manejo da transferência com o paciente acometido pelo FPS ocorre pela via da operação do desejo do analista através dos significantes que o próprio analisando produz. Esses significantes produzidos podem restituir o intervalo entre S1-S2, possibilitando a afânise do sujeito e a articulação entre significantes, produzindo a emergência do desejo e o aparecimento de uma queixa pela via do sintoma neurótico (Fernandéz, 2000). Nicolau e Guerra (2012) afirmam que o trabalho do analista consistirá em escutar esse discurso sobre a doença, discurso que, a princípio, permanece 
fixado a ela, na tentativa de possibilitar, minimamente, um deslizamento de significantes e um esboço de elaboração.

Em uma sessão, Paula iniciou falando sobre a mãe nunca se preocupar muito em "ajudar os outros", característica com a qual sempre resistira em se identificar. Salientou acreditar não ter herdado esse modo de ser da mãe, mas sim do pai, construindo uma hipótese como uma identificação paterna, pois não conviveu com este. Foi-lhe indagado como pensava nessa possível identificação; e sua resposta fez referência ao significante "bom", como algo que poderia ter sido transmitido por seu pai, da ordem de uma herança. Essas intervenções inscrevem-se como reparações através da suplência pelo Nome-do-Pai e promovem um giro no discurso e a remissão do FPS, pois passou a ordenar a sua fala sobre questões de sua história, retirando a fixação de gozo de um só ponto. Sua identificação ao pai foi fundamental para enlaçar o nó borromeano, já que havia uma falha na inscrição do Nome-do-Pai e a holófrase entre o primeiro par de significantes da cadeia, operando-se uma suplência, o que lhe permitiu sair da fixação no gozo do Outro e inscrever algo do seu sintoma que a marcasse como sujeito. Sobre a noção de suplência, nos remeteremos à Lacan quando este aborda o uso do Nome-do-Pai como uma possibilidade de outro enlaçamento para o nó borromeano, protegendo a fantasia do sujeito.

No Seminário RSI, Lacan (1992) atribui ao significante Nome-do-Pai a função de nominação, que leva a uma redistribuição gozosa e a sua articulação ao sintoma. Szapiro (2008) pontua que, para operar sobre o FPS, pode-se trabalhar a partir da suplência, gerador de maior estabilidade ao sujeito: fazendo uso do Nome-do-Pai, pode promover uma regulação de gozo, pois o objeto ao qual o gozo estava fixado se transforma em causa de desejo. Observa que, o que está em jogo, é a possibilidade de uma outra forma de enodamento. Assim, poderá emergir um sujeito com a remissão do FPS, o que leva a um descongelamento da cadeia significante, produzindo uma dialetização do discurso na transferência. Essa operação possibilita um novo saber-fazer com o seu gozo.

Abandonou a repetição de um traço, de um hieróglifo, para falar de uma história, em que a família entra em cena, composta por vários personagens importantes em sua associação livre, ou seja, remeteu-se a outra cena. Nesse caso, como percebemos, a análise, sustentada pelo desejo do analista, pode conduzir o paciente ao seu próprio desejo, desatrelando-o do gozo avassalador do Outro gozador, possibilitando que o mesmo remeta a sua fala ao inconsciente, em busca da construção de um saber sobre a sua verdade. Esta foi a função da analista com os atendimentos, sustentando uma fala inicial fixada, que impedia que o sujeito pudesse constituir um sintoma analítico a ser endereçado a um outro na posição de sujeito suposto saber, permitindo o seu comparecimento como sujeito desejante nos intervalos entre os significantes da cadeia, na medida em que manifestasse formações do inconsciente, manifestando algo do dizer, e não apenas pedaços de real com o seu corpo através de um gozo fixado no órgão. Nicolau (2008) assinala que o enodamento promovido pelo FPS pode sofrer uma passagem para o enodamento pelo Nome-do-Pai, permitindo uma cifração que se direciona a palavra falada.

Como constatamos, no caso de Paula, através da operação em transferência, houve a passagem de um FPS, como uma afecção no corpo impossível de ser interpretada, a um sintoma, passível de ser lido, à medida que sua fala se desloca para representações que remetem ao inconsciente, isto é, apresenta-se articulada com algo de sua dimensão subjetiva e de sua história familiar, na busca da construção de um saber.

A análise de Paula pode operar uma mudança na relação com o seu sofrimento, na medida em que o desejo do analista sustentou sua fala em posição de objeto a, permitindo que algo de seu desejo pudesse aparecer. Paula construiu o seu romance edípico, apresentando aí sua divisão de sujeito, que a marca como faltoso e desejante, retirando-a da apatia e entrega inicial às doenças, isto é, ao gozo específico das afecções. Isso também se deve à presença de uma neurose histérica, na medida em que se percebeu que havia uma inscrição da Lei, mas de maneira inadvertida e com uma falha na nominação simbólica, remetendo a uma insatisfação na busca incessante norteada pelo falo, que permanecia suprimida pelo seu adoecimento corporal.

\section{Referências}

American Psychological Association. (2002). DSM-IV: Manual diagnóstico e estatístico de transtornos mentais. Porto Alegre: Ed. Artes Médicas.

Fernandéz, M. R. (2000). A indução significante no fenômeno psicossomático. Revista da Escola Letra Freudiana: O corpo da psicanálise (27), 317-321.

Freud, S. (1996a). Sobre os fundamentos para destacar da neurastenia: uma síndrome específica intitulada neurose de angústia In J. Strachey (Ed.), Edição Standard Brasileira das Obras Psicológicas Completas de Sigmund Freud (Vol. 3, pp. 87-114). Rio de Janeiro: Imago (Originalmente publicado em 1895)

Freud, S. (1996b). Três ensaios sobre a teoria da sexualidade. In J. Strachey (Ed.), Edição Standard Brasileira das Obras Psicológicas Completas de Sigmund Freud (Vol. 7, pp. 117-231). Rio de Janeiro: Imago. (Originalmente 
publicado em 1905)

Freud, S. (1996c). Recomendações aos médicos que praticam a psicanálise. In J. Strachey (Ed.), Edição Standard Brasileira das Obras Psicológicas Completas de Sigmund Freud (Vol. 12, pp. 145-159). Rio de Janeiro: Imago (Originalmente publicado em 1912)

Lacan, J. (2009). O Seminário, Livro 1: Os escritos técnicos de Freud ( $2^{\mathrm{a}}$ ed.). Rio de Janeiro: Jorge Zahar Editor.

Lacan, J. (1998). A instância da letra no inconsciente ou a razão desde Freud. In J. Lacan, Escritos (pp. 496-533). Rio de Janeiro: Jorge Zahar Editor.

Lacan, J. (2005). O Seminário, Livro 10: A angústia (19621963). Rio de Janeiro: Jorge Zahar Editor.

Lacan, J. (2008). O Seminário, Livro 11: Os quatro conceitos fundamentais da psicanálise (1964) ( $2^{\mathrm{a}} \mathrm{ed}$.). Rio de Janeiro: Jorge Zahar Editor.

Lacan, J. (2001). O lugar da psicanálise na medicina. Revista Opção Lacaniana, 32, 8-14.

Lacan, J. (1992). Séminaire XXII. RSI (1974-1975) [Tradução para circulação interna, Inédito].

Lacan, J. (1993). Conferencia in Ginebra sobre el síntoma. In J. Lacan, Intervenciones y textos 2 (pp. 115-144). Buenos Aires: Manantial.

Nicolau, R. F. (2008). A psicossomática e a escrita do real. Revista Mal-Estar e Subjetividade, 8(4), 959-990.

Nicolau, R. F., \& Guerra, A. M. C. (2012). O fenômeno psicossomático no rastro da letra. Estudos e Pesquisa em Psicologia, 12(1), 226-241.

Ornellas, J. (2004). Luzes sinistras. Revista da Escola Letra Freudiana: O corpo do Outro e a criança, (33), 113126.

Szapiro, L. (2008). Elementos para una teoría y clínica lacaniana del fenómeno psicosomático. Buenos Aires: Grama Ediciones.

Wartel, R., Merlet, A., Laurent, E., Blancard, M.-H., Josselin, F., Guir, J., Kaltenbeck, F., Valas, P., \& Miller, J.-A. (2003). Que esperam de nós os médicos? In R. Wartel (Coord.), Psicossomática e Psicanálise ( $2^{\mathrm{a}} \mathrm{ed}$., pp. 9-15). Rio de Janeiro: Jorge Zahar Editor.
Endereço para correspondência:

Ingrid de Figueiredo Ventura

Endereço: Praça Benedito Calixto, 186, ap. 96.

Bairro: Pinheiros. São Paulo - SP. CEP: 05406-040.

E-mail: ifigueiredoventura@gmail.com.

\section{Endereço para correspondência:}

Roseane Freitas Nicolau

Endereço: Rua dos Mundurucus, 1553, ap. 501. Bairro:

Batista Campos. Belém - PA. CEP: 66035-360.

E-mail:rf-nicolau@uol.com.br 